\title{
Massa auricular direita
}

\author{
Right atrial mass
}

Apresentamos o caso de um homem de 55 anos, com hepatite $\mathrm{C}$ crónica e com um volumoso hepatocarcinoma, cuja apresentação inicial foi como massa auricular direita. Apesar de ter sido descrita previamente a extensão endovascular deste tipo de tumor até ao interior das cavidades cardíacas direitas, a raridade e exuberância das imagens de ecocardiograma e TAC tornam invulgar e excepcional este caso. 0 hepatocarcinoma (HCC) é o tumor hepático mais frequente, o quinto tipo de cancro mais comum e a terceira maior causa de morte por cancro no mundo. Na Europa, a incidência é inferior a 5 casos por 100.000 habitantes-ano ${ }^{1}$. É mais frequente no homem e as principais causas são a infecção crónica pelo Vírus da Hepatite C e o alcoolismo crónico².

Apresentamos o caso de um homem de 55 anos, com hepatite $C$ crónica (genótipo 1a) conhecida há 30 anos, tratado com Interferão peguilado e Ribavirina, sem resposta; com cirrose hepática Child A e sinais de hipertensão portal. Observado por quadro de cansaço fácil, aumento do perímetro abdominal e febre. Constatado sopro cardíaco de novo, pelo que realiza um ecocardiograma transtorácico, que revela uma massa volumosa hipoecogénica no interior da aurícula direita $(A D)$, condicionando alguma obstrução à entrada do fluxo na mesma (figura 1a, plano de 4 câmaras apical). A caracterização adicional por ecocardiograma transesofágico demonstra a origem extracardíaca da massa, que entra na AD a partir da veia cava inferior (VCI) (figura 1b, plano bicava), a sua aparência multilobulada (figura 1c, plano câmara de entrada - saída do ventrículo direito) e a sua relação de proximidade mas não de continuidade com o septo interauricular (figura 1d, aquisição 3D). A TAC toraco-abdominal revela um parênquima hepático heterogéneo, no qual se distingue a mesma massa central, hipodensa, de difícil delimitação, compatível com um HCC, e que se extende ao longo da VCl até à AD, bem como toda a extensão da veia porta, ocluindo-a por completo (figura 2). A envolver os vasos portais identificam-se várias estruturas vasculares serpiginosas, em relação com transformação cavernomatosa (figura 2d). Em redor, observam-se múltiplas formações nodulares hipodensas - prováveis lesões secundárias. Na figura 3, além da massa visível na $A D$, destacam-se ainda sinais de tromboembolismo pulmonar nos ramos segmentares para o lobo inferior direito.

A extensão cardíaca de tumores primários de outros órgãos verifica-se por via linfática, hematogénica, ou por extensão direta endovenosa. Quer tumores benignos, quer malignos podem apresentar este tipo de extensão endovascular até ao coração. O HCC apresenta invasão cardíaca em 1.5\% a 18.3\% dos casos, mais frequentemente invadindo 0 pericárdio, e raramente atingindo as cavidades cardíacas. ${ }^{3} 0$ crescimento tumoral pode ser ocasionalmente subclínico até que se desenvolva uma massa de grandes dimensões. ${ }^{2}$ Apesar de já ter sido descrita previamente a extensão do HCC à VCl e AD, a sua prevalência é de apenas 1 a $4 \%{ }^{3}$, daí a raridade e importância deste caso clínico.

\section{Bibliografia}

1. Tejeda-Maldonado J, García-Juárez I, Aguirre-Valadez J, González-Aguirre A, Vilatobá-Chapa M, Armengol-Alonso A et al. Diagnosis and treatment of hepatocellular carcinoma: An update. World J Hepatol. $2015 ; 7: 362-76$.

2. Vieito N, Montañés A, Blanco MD. Hepatocarcinoma: estado actual. Galicia Clin. 2014; 75: 171-81.

3. Baca-López F, Ramírez-Arias E, Rayas-Gómez A, Bernal-Ruiz E, Saturno-Chiu G. Hepatocellular carcinoma with invasion into right cardiac cavities: report of a case and literature review. J Am Soc Echocardiogr. 2004; 17: 192-4.

\section{Diagnóstico: Hepatocarcinoma - apresentação como massa auricular direita}

\section{Joana Urbano ${ }^{1}$, Gonçalo Pestana² \\ ${ }^{1}$ Serviço de Medicina Interna e ${ }^{2}$ Serviço de Cardiologia do Centro Hospitalar de São João, Porto, Portugal.}

\section{Correspondencia: joanaurb@gmail.com}

Como citar este artículo: Urbano J., Pestana G.

Massa auricular direita. Galicia Clin 2016; 77 (1): 42

Recibido: 13/10/2015; Aceptado: 25/10/2015
Fig 1. Ecocardiograma transtorácico: massa volumosa hipoecogénica no interior da aurícula direita (AD)

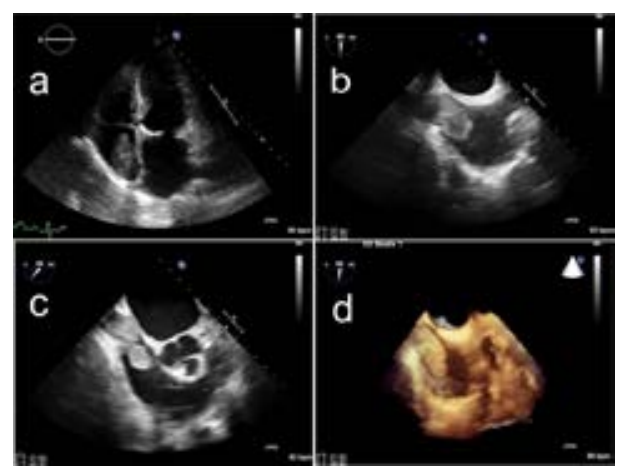

Fig 2. TAC toraco-abdominal: massa hepática central, hipodensa, de difícil delimitação, compatível com um HCC

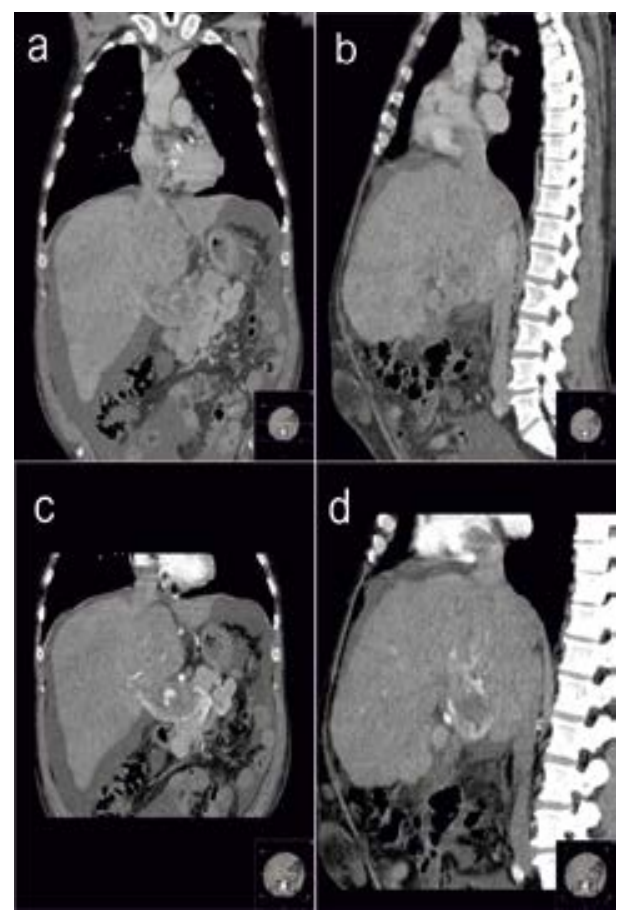

Fig 3. Sinais de tromboembolismo pulmonar nos ramos segmentares para o lobo inferior direito

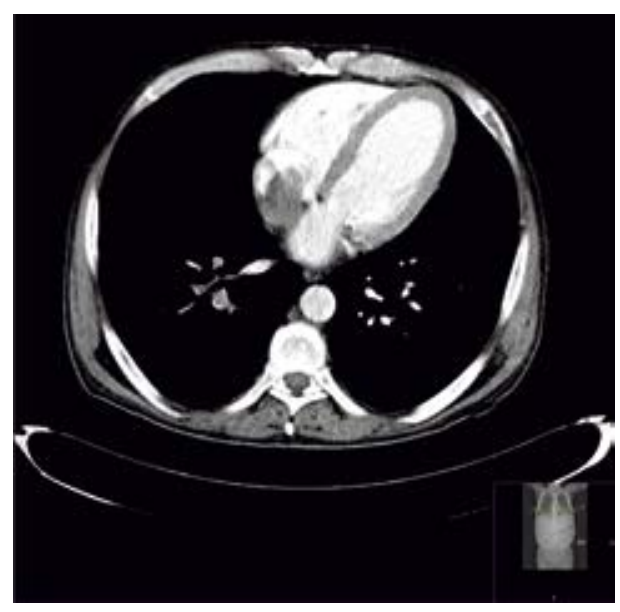

